\title{
Vaginitis in Intrauterine Contraceptive Device Users
}

\author{
Fatemeh Shobeiri ${ }^{*}$, Mansour Nazari ${ }^{2}$ \\ ${ }^{1}$ Research Center for Child \& Maternity Care (RCCMC), Hamadan University of Medical Sciences, Hamadan, Iran \\ ${ }^{2}$ Department of Medical Entomology, School of Medicine, Hamadan University of Medical Sciences, Hamadan, \\ Iran \\ Email: ${ }^{*}$ fshobeiri@yahoo.com
}

Received 1 April 2014; revised 4 May 2014; accepted 11 May 2014

Copyright (C) 2014 by authors and Scientific Research Publishing Inc.

This work is licensed under the Creative Commons Attribution International License (CC BY). http://creativecommons.org/licenses/by/4.0/

(c) (7) Open Access

\begin{abstract}
Objectives: This study aimed to assess clinical, microbial changes in IUD users and other contraceptive methods in referent to urban health centers in Hamadan city, Iran. Methods: Detailed history and gynecological examination were conducted on women (IUD users, $n=100$ ) or other contraceptive methods (controls, $n=160$ ) in the health centers. Results: Frequencies of the different vaginal pathogens, high indices of infection by bacterial vaginosis $(12.0 \%)$ candida albicance (7.0\%) and low indices of trichomoniasis $(5.0 \%)$ were found in present study, but none of them in both groups was significant. Menorrhagia was more frequent among women with IUD than that among women without IUD ( $P<0.05)$. A trend of erosion cervix and dysmenorrhea being more frequent among women with IUD was also found $(P<0.05)$. Conclusions: IUD is the safety in general; however, an increase occurred in the frequency of vaginitis.
\end{abstract}

\section{Keywords}

Intrauterine Device, Vaginitis, Microbial Agent, Erosion Cervix

\section{Introduction}

The insertion of intrauterine devices (IUD) is one of the most prevalent and effective reversible methods of contraception worldwide, and millions of IUDs are inserted yearly. However, it is used far less often than experts believe it should be. Basically, this is believed to be the result of the concerns of clinicians for the risk of complications linked to its use, particularly pelvic inflammatory disease (PID) and subsequent sequels [1] [2]. The most common medical reasons for early discontinuation of IUD are bleeding and/or pain along with genital in-

${ }^{*}$ Corresponding author. 
fections [3]. Most studies have found an increased risk of pelvic inflammatory disease and its squeal, ranging from two-fold to nine-fold, among IUD users [4]. The incidence rate of PIDs among IUD users as reported from different studies depends heavily on the definition used and the means available for diagnosing PIDs. It varies by almost ten-fold from 1 per 100 to 1 per 1000 women in different publications [5]. Bacterial vaginosis is the most common vaginal infection among reproductive-age women and several studies have demonstrated a higher prevalence of this infection among IUD users in different countries [2] [6] [7]. It has been suggested that the presence of bacterial vaginosis in IUD insertion could also lead to an increased risk of complications in the first trimester of use [4]. Thus, screening and treatment for bacterial vaginosis prior to IUD insertion have been considered. Clinical, microbial monitoring of women using IUD is important for ascertaining their side effects, risk of genital tract infection and carcinogenic potential. This study aimed to assess clinical, microbial changes in IUD users and other contraceptive methods in referent to urban health centers in Hamadan city, Iran.

\section{Materials and Methods}

This study was carried out in urban health centers is Hamadan city, Iran. The institutional research board approval was obtained and all volunteers signed an informed consent prior to entering the study. This study comprised of study subjects $(n=100)$ using T-Cu-380A IUD who attended family planning clinic for routine follow up. The control subjects $(n=160)$ were women who had did not have IUD and using other contraception methods such as; hormonal, barriers and surgery methods. The subjects were chosen randomly irrespective of their complaints. Data collection was on the base of questionnaire and gynecological examination. Detail history, clinical examination and gynecological examination i.e. per speculum and per vaginal examination were done in all the women. Per speculum examination was carried out to look for IUD, condition of vagina and cervix and for discharge. Vaginal discharge was collected from posterior fornix for Gram staining, KOH mount, wet mount and in a transport medium for culture and sensitivity testing. Bimanual examination was undertaken to rule out pelvic inflammatory disease. Data processing and statistical analysis were performed using SPPS 16.0.

\section{Results}

A total of 100 IUD users and 160 matched other contraceptive methods were studied. The type of IUD used was T-Cu-380A. The mean of duration of IUD use was $3.8 \pm 1.9$ years.

The general information about the selected subjects is presented in Table 1. A clinical sign was significantly different in both of groups $(\mathrm{P}<0.05)$. Most women $(56.5 \%)$ were within 20 - 29 years. Majority of women (56.9\%) were in elementary level, and (93.0\%) were housewives. About half of women (43.8\%) surveyed had 3 and more children, and (50.7\%) of women had positive clinical signs. No significant differences were observed between the two groups of women regarding selected socio demographic characteristics.

Chief complains of IUD users included menorrhagia (81.0\%), erosion cervix (68.0\%), dysmenorrhea (66.0\%), dysparroina (62.0\%), backache (60.0\%), vaginal discharge (53.0\%), spotting (44.0\%) and urinary problems (40.0\%) had shown in Table 2. On per speculum examination, erosion cervix was significantly higher in IUD users compared to other contraceptive methods $\left(\mathrm{X}^{2}=3.92, \mathrm{df}=1, \mathrm{P}=0.04\right)$ (Table 2).

Table 3 had presented the principal clinical and laboratory finding among the study subjects. Vaginal discharge smear revealed comparable positively for trichomonas vaginalis. Gram stain findings of vaginal discharge were not significantly different in two groups except for lactobacilli and coagulase negative staphylococci. Gardnerella rate in IUD users and other contraceptive methods were $12 \%$ and $4.4 \%$, respectively $(\mathrm{P}=0.11)$. Vaginal discharge bacterial culture grew organisms in nearly all the IUD users and other contraceptive methods. However rates of individual organisms isolated was not significantly different. Sterile culture was significantly higher in IUD users compared to other contraceptive methods $\left(X^{2}=9.6, \mathrm{df}=1, \mathrm{P}=0.03\right)$.

\section{Discussion}

The present study found that a significant proportion of women using IUD had gynecological symptoms and cervical erosion. There was no significant increase in cervicovaginal infection however the study did not at quantitative aspect of it. Aggarval et al. had reported perceived symptoms in 100 IUD users as: no problems (20.0\%), too much bleeding (18.0\%), backache (54.0\%), abdominal pain (34.0\%), dysmenorrheal (14.0\%), psychosexual problems (6.0\%), dyspareunia (22.0\%), vaginal discharge (46.0\%) [3]. In addition, in follow-up study of 223 IUD users, women with and without bacterial vaginosis had been found to be abnormal bleeding (30.4\% 
Table 1. General characteristics of selected women.

\begin{tabular}{|c|c|c|c|}
\hline Characteristic & IUD users $(\mathrm{n}=100)$ & Other methods $(n=160)$ & $\mathrm{P}$ \\
\hline \multicolumn{4}{|l|}{ Age (\%) } \\
\hline $20-29$ & 78.0 & 35.0 & \\
\hline $30-39$ & 20.0 & 32.0 & 0.26 \\
\hline$\geq 40$ & 2.0 & 33.0 & \\
\hline \multicolumn{4}{|c|}{ Age at marriage (\%) } \\
\hline$\leq \mathbf{2 0}$ & 94.0 & 80.0 & 0.16 \\
\hline$>\mathbf{2 0}$ & 6.0 & 20.0 & \\
\hline \multicolumn{4}{|l|}{ Education (\%) } \\
\hline Elementary & 45.0 & 68.8 & \\
\hline College & 44.0 & 8.1 & 0.98 \\
\hline Graduate & 11.0 & 23.1 & \\
\hline \multicolumn{4}{|l|}{ Occupation (\%) } \\
\hline Housewife & 96.0 & 90.0 & 0.16 \\
\hline Employed & 4.0 & 10.0 & \\
\hline \multicolumn{4}{|l|}{ No. of parity (\%) } \\
\hline 1 & 47.0 & 20.0 & \\
\hline 2 & 19.0 & 26.3 & 0.00 \\
\hline$\geq 3$ & 34.0 & 53.7 & \\
\hline \multicolumn{4}{|c|}{ Clinical signs (\%) } \\
\hline Yes & 57.0 & 44.4 & 0.00 \\
\hline No & 43.0 & 55.6 & \\
\hline
\end{tabular}

${ }^{\mathrm{a}}: \mathrm{P}<0.05$, Pearson chi-square.

Table 2. Percentage of clinical signs in IUD users and other methods.

\begin{tabular}{|c|c|c|c|}
\hline Variable & IUD users & Other methods & $\mathrm{P}$ \\
\hline Dysmenorrhea & 46.0 & 40.0 & 0.20 \\
\hline Dysparroina $^{a}$ & 62.0 & 38.7 & 0.00 \\
\hline Spotting ${ }^{a}$ & 44.0 & 34.4 & 0.00 \\
\hline Menorrhagia & 81.0 & 15.6 & 0.26 \\
\hline Backache & 60.0 & 58.7 & 0.55 \\
\hline Uriary problems & 40.0 & 32.5 & 0.13 \\
\hline Vaginal discharge & 53.0 & 46.9 & 0.02 \\
\hline Erosion cervix ${ }^{a}$ & 68.0 & 21.2 & 0.04 \\
\hline
\end{tabular}

${ }^{\mathrm{a}}$ : $\mathrm{P}<0.05$, Pearson chi-square.

and $17.2 \%$ ) and dysmenorrhea (34.8\% and 13.9\%), respectively [4]. Cervical erosion was present in a significant proportion of study subjects compared to controls. Other investigators were found to have cervical erosion in $3.3 \%$ - $20.0 \%$ of the women using IUD in different population [3] [4] [8]. Neale et al. had reported that women were significantly more likely to have developed an abnormal vaginal discharge 4 - 6 weeks after insertion of an IUD [9]. In relation to the frequencies of the different vaginal pathogens, high indices of infection by bacterial vaginosis were found in present study (12.0\%), candida albicance $\mathbf{7 . 0 \% )}$ and low indices of trichomoniasis (5.0\%). These rates are similar to those observed by other authors [10] [11]. Auler et al. indicated that the presence of the biofilm on the surface of the IUD was as an important risk factor for recurrent vulvovaginal candidiasis [12]. In another study of 253 women (aged from 20 - 48 years) with abnormal vaginal discharges applied to gynecology outpatient clinic, it was found that T. vaginalis was detected in 13 of 114 IUD users 
Table 3. Finding of clinical \& laboratory examination in IUD users and other methods (\%).

\begin{tabular}{|c|c|c|c|}
\hline Variable & IUD users & Other methods & $\mathrm{P}$ \\
\hline \multicolumn{4}{|l|}{ Gram stain of vaginal discharge } \\
\hline Gram positive cocci & 11.0 & 24.4 & 0.51 \\
\hline Lactobacilli $^{\mathrm{a}}$ & 5.0 & 10.6 & $0.01 *$ \\
\hline Gram positive bacilli & 27.0 & 16.2 & 0.06 \\
\hline Gram negative bacilli & 12.0 & 7.5 & 0.10 \\
\hline Gram positive gram negative cocco bacilli & 11.0 & 9.4 & 0.07 \\
\hline Coagulase negative \& Staghylococci $i^{\mathrm{a}}$ & 15.0 & 7.5 & $0.01 *$ \\
\hline Yeast cells & 7.0 & 4.4 & 0.51 \\
\hline \multicolumn{4}{|l|}{ Wet mount positive for Trichomonas vaginalis } \\
\hline \multicolumn{4}{|l|}{ Vaginal discharge culture } \\
\hline Lactobacilli & 4.0 & 5.6 & 0.06 \\
\hline Klebciella & 1.0 & 0.62 & 0.08 \\
\hline Diftroeid & 2.0 & 2.5 & 0.12 \\
\hline E. coli & 12.0 & 5.0 & 0.10 \\
\hline Kandida albicance & 7.0 & 5.0 & 0.10 \\
\hline E. coli \& Klebciella & 6.0 & 0.0 & 0.22 \\
\hline Staphylococcus epidermis & 12.0 & 11.9 & 0.06 \\
\hline Staphylococcus aureus & 10.0 & 18.7 & 0.07 \\
\hline Entrobacter & 8.0 & 9.4 & 0.13 \\
\hline Gardnerella & 12.0 & 4.4 & 0.11 \\
\hline Entrococci & 3.0 & 4.4 & 0.08 \\
\hline Sterile $^{\mathbf{a}}$ & 23.0 & 32.5 & $0.03^{*}$ \\
\hline
\end{tabular}

${ }^{\mathrm{a}}$ : P $<0.05$, Pearson chi-square

(14.70\%) [13]. T. vaginalis is the cause of vulvovaginitis and women with abnormal vaginal discharges should be investigated for possible trichomoniasis. In our study, detection of a higher rate of $T$. vaginalis infection in IUD users means that IUD usage might increase the risk of Trichomonas infection. These data are compatible with those in other publications [11] [13]-[15]. Bacterial vaginosis is the most common vaginal infection among reproductive-age women and several studies have demonstrated a higher prevalence of this infection among IUD users in different countries [4] [6] [7] [9] [16]. Because of differences in populations studied and in diagnostic tests used, it is not surprising that estimates of disease prevalence have varied greatly from study to study.

These findings give some support that presence of IUD might facilitate changes in the vaginal ecosystem and possibility of BV in some IUD users. Therefore, screening women for these cervical infections before insertion is recommended by most guidelines.

Nevertheless, menorrhagia or dysmenorrheal are by themselves important complaints that can lead to discontinuation of the methods, and any possible therapies to correct these complaints are desirable. Thread of IUD tail being a source of constant irritation may be responsible for cervical erosion. It may provide a conduit for ascending infection from vagina. Though cervical erosion is not considered as something with serious implication but it may be responsible for vaginal discharge and other symptoms in the users [4]. The data support the hypothesis that IUD might change cervico vaginal environment, and suggest that women with IUD may be at a higher risk for vulvovaginal infection. The local irritative and inflammatory effect of intrauterine devices basically causes reactive and regenerative changes mostly in glandular cells. Intrauterine devices disrupt the genital flora and significantly increase the frequency of genital infection by creating a foreign body reaction. Therefore, screening women for these cervical infections before insertion is recommended by most guidelines.

\section{Conclusion}

In conclusion, influence of IUD use on the occurrence of vaginal flora changes has remained as a controversial 
issue. The presence study reiterates the safety of IUD in general; however the users had higher rates of menorrhagia, erosion cervix and dysmenorrhea. Thus these women require a regular follow-up for counseling and clinical examination.

\section{Acknowledgements}

The authors sincerely acknowledge the Hamadan University of Medical Sciences in Iran for their valuable support and participation.

\section{Authors' Contributions}

FS carried out the study design, participated in data collection and drafted the manuscript. MN participated in the design of the study and performed the statistical analysis. FS and MN conceived of the study, and participated in its design and coordination. All authors read and approved the final manuscript.

\section{Competing Interests}

The authors declare that they have no competing interests.

\section{References}

[1] Steenland, M.W., Zapata, L.B., Brahmi, D., Marchbanks, P.A. and Curtis, K.M. (2013) Appropriate Follow Up to Detect Potential Adverse Events after Initiation of Select Contraceptive Methods: A Systematic Review. Contraception, 87, 611-624. http://dx.doi.org/10.1016/j.contraception.2012.09.017

[2] Donders, G.G., Berger, J., Heuninckx, H., Bellen, G. and Cornelis, A. (2011) Vaginal Flora Changes on Pap Smears after Insertion of Levonorgestrel-Releasing Intrauterine Device. Contraception, 83, 352-356.

http://dx.doi.org/10.1016/j.contraception.2010.08.007

[3] Agarwal, K., Sharma, U. and Acharya, V. (2004) Microbial and Cytopathological Study of Intrauterine Contraceptive Device Users. Indian Journal of Medical Sciences, 58, 394-399.

[4] Ferraz do Lago, R., Simões, J.A., Bahamondes, L., Camargo, R.P., Perrotti, M. and Monterio, I. (2003) Follow-Up of Users of Intrauterine Device with and without Bacterial Vaginosis and Other Cervicovaginal Infections. Contraception, 68, 105-109. http://dx.doi.org/10.1016/S0010-7824(03)00109-4

[5] Meirik, O. (2007) Intrauterine Devices_-Upper and Lower Genital Tract Infections. Contraception, 75, S41-S47. http://dx.doi.org/10.1016/j.contraception.2006.12.017

[6] Lessard, T., Simões, J.A., Discacciati, M.G., Hidalgo, M. and Bahamondes, L. (2008) Cytological Evaluation and Investigation of the Vaginal Flora of Long-Term Users of the Levonorgestrel-Releasing Intrauterine System (LNG-IUS). Contraception, 77, 30-33. http://dx.doi.org/10.1016/j.contraception.2007.09.009

[7] Watcharotone, W., Sirimai, K., Kiriwat, O., et al. (2004) Prevalence of Bacterial Vaginosis in Thai Women Attending the Family Planning Clinic, Siriraj Hospital. Journal of the Medical Association of Thailand, 87, 1419-1424.

[8] Ocak, S., Cetin, M., Hakverdi, S., Dolapcioglu, K., Gungoren, A. and Hakverdi, A.U. (2007) Effects of Intrauterine Device and Oral Contraceptive on Vaginal Flora and Epithelium. Saudi Medical Journal, 28, 727-731.

[9] Neale, R., Knight, I. and Keane, F. (2009) Do Users of the Intrauterine System (Mirena) Have Different Genital Symptoms and Vaginal Flora than Users of the Intrauterine Contraceptive Device? International Journal of STD \& AIDS, 20, 423-424. http://dx.doi.org/10.1258/ijsa.2008.008391

[10] Tosun, I., Aydin, F., Kaklikkaya, N. and Yazici, Y. (2003) Frequency of Bacterial Vaginosis among Women Attending for Intrauterine Device Insertion at an Inner-City Family Planning Clinic. European Journal of Contraception and Reproductive Health Care, 8, 135-138. http://dx.doi.org/10.1080/ejc.8.3.135.138

[11] McClelland, R.S., Sangare, L., Hassan, W.M., et al. (2007) Infection with Trichomonas vaginalis Increases the Risk of HIV-1 Acquisition. The Journal of Infectious Diseases, 195, 698-702. http://dx.doi.org/10.1086/511278

[12] Auler, M.E., Morreira, D., Rodrigues, F.F., et al. (2010) Biofilm Formation on Intrauterine Devices in Patients with Recurrent Vulvovaginal Candidiasis. Medical Mycology, 48, 211-216. http://dx.doi.org/10.3109/13693780902856626

[13] Sönmez Tamer, G., Keçeli Ozcan, S., Yücesoy, G. and Gacar, G. (2009) The Relation between Trichomoniasis and Contraceptive Methods. Türkiye Parazitoloji Dergisi, 33, 266-269.

[14] Nasir, J.A., Najmi, J., Tahir, F., Asghar, M.N. and Iqbal, J. (2005) Trichomonas vaginalis in Vaginal Smears of Women Using Intrauterine Contraceptive Device. Pakistan Journal of Medical Research, 44, 114-116. 
[15] Mahdi, N.K., Gany, H. and Sharief, M. (2001) Infection Rate of Trichomonas vaginalis According to Contraceptive Methods. Eastern Mediterranean Health Journal, 7, 918- 924.

[16] Shobeiri, F. and Nazari, M. (2006) A Prospective Study of Genital Infections in Hamadan-Iran. Southeast Asian Journal of Tropical Medicine and Public Health, 37, 174-177. 